\title{
Immediate Effect of Hot Pack versus Kinesiotape and Hot Pack on Pain in Primary Dysmenorrhea
}

\author{
Revati Joshi ${ }^{1}$, Shweta Pachpute ${ }^{2}$ \\ ${ }^{1}$ Intern, LSFPEF College of Physiotherapy, Pune, India. \\ ${ }^{2}$ Professor and HOD of Musculoskeletal Department, LSFPEF College of Physiotherapy, Pune, India. \\ Corresponding Author: Revati Joshi
}

\begin{abstract}
Background: Primary dysmenorrhea is one where there is no identifiable pelvic pathology It is mostly confined to adolescents and young adult female. The pain begins a few hours before or just with the onset of menstruation. The severity of pain usually lasts for few hours and may extend beyond 48 hours. The pain is spasmodic and confined to lower abdomen and may radiate to back. Systemic discomforts like nausea, vomiting, fatigue, headache, stress, nervousness, fainting may be associated.
\end{abstract}

Purpose: To study the immediate effect of Hot Pack versus Kinesiotape and Hot Pack on pain in primary dysmenorrhea.

Methods: The study consists of fifty participants with primary dysmenorrhea.

Sampling Method: Simple Random sampling by tossing the coin and allocation of the participants to the two groups: Group A and Group B

Selection Criteria -Inclusion Criteria: Age Group 18-25 yrs., Females suffering from symptoms of primary dysmenorrhea, females having 5 and above score on NPRS.

Exclusion Criteria: Females having underlying conditions related in gynaecological origin, musculoskeletal dysfunction, irregular menstrual cycle.

Results: The results of the study showed that there was a significant reduction in the pain intensity $(\mathrm{p}<0.05)$ in both the groups. Based on statistical analysis, there was no significant adjunct effect of kinesiotape seen as compared to only hot pack.

Conclusion: Study concludes that clinically Hot Pack as well as Kinesiotape both are effective in alleviating pain in primary dysmenorrhea. Kinesiotape showed no significant adjunct effect as compared to only hot pack.

Keywords: Primary dysmenorrhea, Hot Pack, Kinesiotape.

\section{INTRODUCTION}

Menstruation is the visible manifestation of cyclic physiologic uterine bleeding due to the shedding of the endometrium following invisible interplay of hormones mainly through hypothalamus pituitary ovarian axis. (1) Dysmenorrhea literally means painful menstruation. There are two types of dysmenorrhea - Primary and Secondary. ${ }^{(1)}$ Primary dysmenorrhea is one where there is no identifiable pelvic pathology. (1) It is mostly confined to adolescents and young adult female. Pain is related to dysrhythmic uterine contractions. Under the action of progesterone, prostaglandins (PGF 2 alpha, PGE 2) are synthesized from the secretory endometrium. PGF2alpha is a strong vasoconstrictor which causes ischemia of the myometrium. Due to this, there is increased myometrial contraction with or without dysrhythmia. The pain begins a few hours before or just with the onset of menstruation. The severity of pain usually lasts for few hours and may extend beyond 48 hours. The pain is spasmodic and 
confined to lower abdomen and may radiate to the back and medial aspects of the thighs. Systemic discomforts like nausea, vomiting, fatigue, diarrhoea, headache, tachycardia, pallor, fainting may be associated. Dysmenorrhea pain can be considerably disabling and is associated with a restriction of physical and daily activities. Pain is one of the largest contributors to poor quality of life.

Hot pack is the conventional method used for relieving menstrual pain. The menstrual pain is reduced by dilation of small blood vessels, increase in the local blood flow and activation of pain gate mechanism. (2)(3)

Kinesiology tape was invented by Dr. Kenzo Kase and Nitto Denko. The adhesion of the $\mathrm{K}$ tape stimulates the mechanoreceptors in the skin. These proprioceptive afferents run to the dorsal horn and inhibit the relaying of nociception, thus reducing the pain. The concentration of pain causing substances such as histamine and prostaglandin in the bloodstream are reduced aiding in the decrease of pain. The application of kinesiotape causes the skin to form convolutions which lift the skin. Theories suggest that these convolutions encourage regeneration of the tissues by increasing the interstitial space and alleviating interstitial pressures. This decrease in pressure also decompresses subcutaneous nociceptors, leading to decreased pain. ${ }^{(4)}$

Due to menstrual pain, the capacity to perform day to day activities is reduced. Many girls take leave from colleges and job as the pain is not tolerable. Many girls find it difficult to carry out their leisure time activities like dancing, sports, etc. due to menstrual pain. In severe cases of Primary Dysmenorrhea, women often find it difficult to even get out of bed. Very few alternatives are available for reducing menstrual pain till now.

Traditionally, superficial heating has been used in different forms (e.g., hot water bags, towels or bottles) to ease menstrual pain. For women with dysmenorrhea, the application of superficial heat can reduce muscle tension and relax abdominal muscles to reduce pain caused by muscle spasms.

Although there is extensive data on the effects of kinesiotaping on pain in musculoskeletal disorders. There is some literature available on the effects of kinesiotaping in primary dysmenorrhea (5) (6) (7). These studies have investigated effect of $\mathrm{K}$ tape on pain in primary dysmenorrhea and applied $\mathrm{K}$ tape 10-14 days prior to menstrual cycle and continued throughout the menstrual cycle but there is no study available in literature who has found out the immediate effect of $\mathrm{K}$ tape on pain in primary dysmenorrhea.

So the aim is to study the immediate effect of Hot Pack versus Kinesiotape and Hot Pack on pain in primary dysmenorrhea. The objective of the study is to find out immediate effect of Hot Pack on pain in Primary dysmenorrhea, to find out immediate effect of Kinesiotape and Hot Pack on pain in Primary dysmenorrhea, to compare the immediate effects of Hot Pack versus immediate effects of Kinesiotape and Hot Pack on pain in Primary dysmenorrhea.

\section{MATERIALS AND METHODS}

Type of study: Experimental

Sample Method: Simple Random Sampling

Sample Size: 50

Study Area: Pune

Study Duration: 6 months

Outcome measure: Numerical Pain rating scale (NPRS)

\section{Inclusion Criteria:}

1. Age Group 18-25 yrs.

2. Females suffering from symptoms of primary dysmenorrhea.

3. Females having 5 and above score on Numerical Pain Rating Scale (NPRS)

\section{Exclusion Criteria}

1. Females having underlying conditions related in gynaecological origin.

2. Females having musculoskeletal conditions. 

dysmenorrhea.

3. Females having irregular menstrual cycle.

\section{PROCEDURE}

Ethical committee clearance was obtained and permission was taken from the department. Written consent was taken from the subjects who fulfilled the inclusion criteria. The subjects were divided in two groups - Group A (Hot Pack) $(\mathrm{n}=25)$ and Group B (Kinesiotape and Hot Pack) ( $=$ 25 ). The pain intensity was taken prior to the intervention by Numerical Pain Rating Scale (NPRS).

For Group A - Hot Pack was applied to group A on $1^{\text {st }}$ day of menstrual cycle. Hot Pack was applied on abdomen and back for 10 min each. Pain intensity was again recorded by NPRS on $1^{\text {st }}$ day of menstrual cycle.

For Group B -K tape was applied to Group $\mathrm{B}$ on $1^{\text {st }}$ day of menstrual cycle. $\mathrm{K}$ tape was applied using ligament technique. For the dorsal application, the subject stood with trunk flexed and the tape was fixed over sacroiliac joint with maximum tension. The tape ends were fixed without tension. For the ventral application, the patient stood with trunk extended and the tape was fixed above symphysis with maximum tension. The tape ends were fixed without tension. After applying kinesiotape, Hot Pack was applied on abdomen and back for $10 \mathrm{~min}$ each. Pain intensity was again recorded by NPRS on $1^{\text {st }}$ day of menstrual cycle.

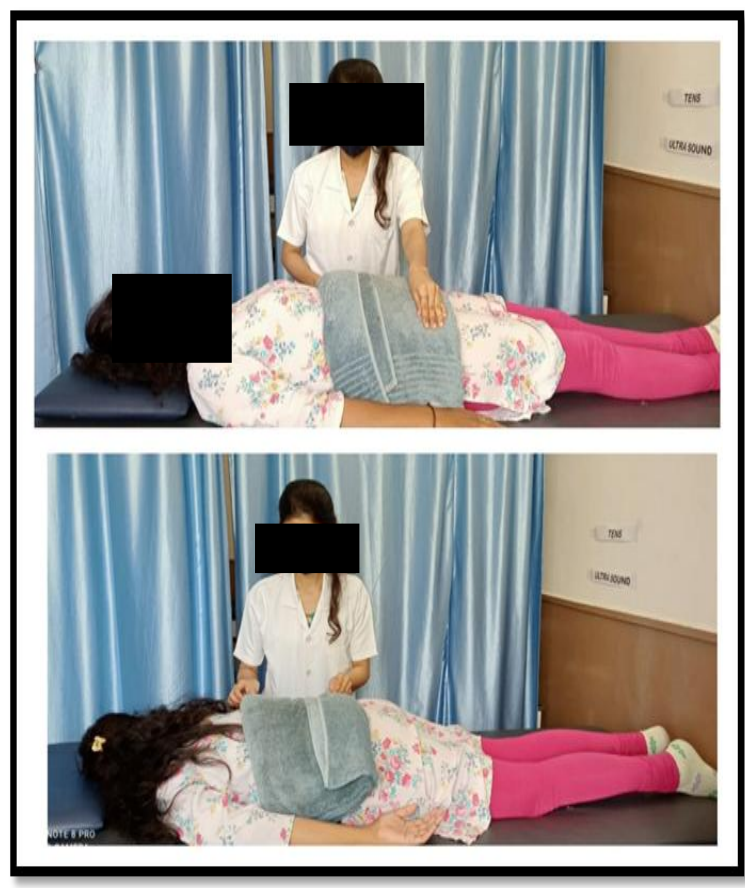

Figure 1 - Group A (Hot Pack)

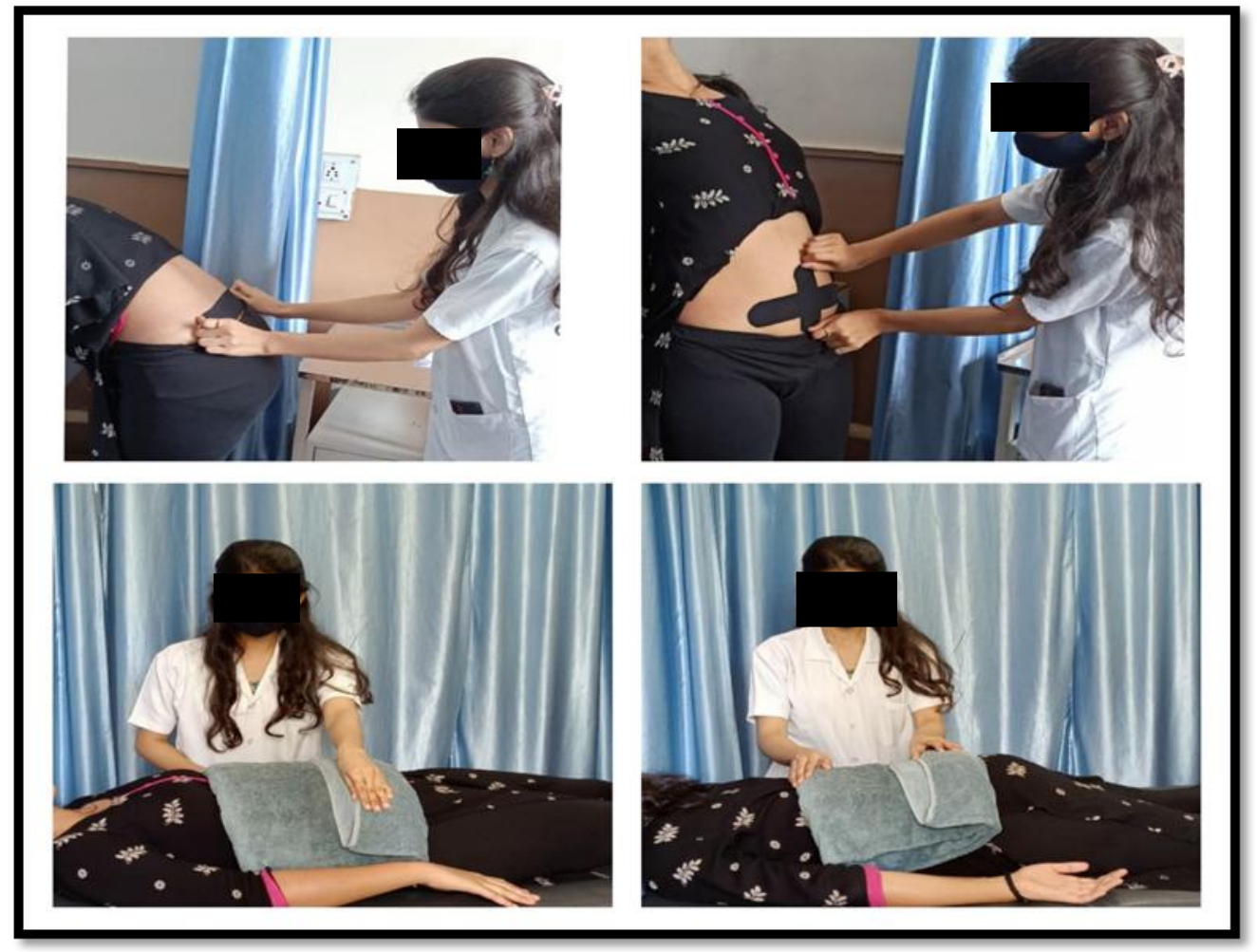

Figure 2-Group B (Kinesiotape and Hot Pack) 
Revati Joshi et.al. Immediate effect of hot pack versus kinesiotape and hot pack on pain in primary dysmenorrhea.

\section{STATISTICAL ANALYSIS}

1. 1Data was collected and analyzed. Paired T test was used within group

2. Unpaired $\mathrm{T}$ test was used in between the groups.

3. For Statistical analysis, Instat Software was used.

\section{RESULTS}

Table 1 -Pre and Post Hot Pack application

\begin{tabular}{|l|l|l|l|l|l|}
\hline $\begin{array}{l}\text { Group } \\
\text { A }\end{array}$ & Mean & SD & P value & $\begin{array}{l}\text { T } \\
\text { value }\end{array}$ & $\begin{array}{l}\text { Mean } \\
\text { Difference }\end{array}$ \\
\hline Pre & 6.04 & 1.098 & $<0.0001$ & 8.513 & 2.280 \\
\hline Post & 3.76 & 1.393 & & & \\
\hline
\end{tabular}

The above table shows that there is significant change in Pre and Post hot pack application on pain rating using NPRS scale.

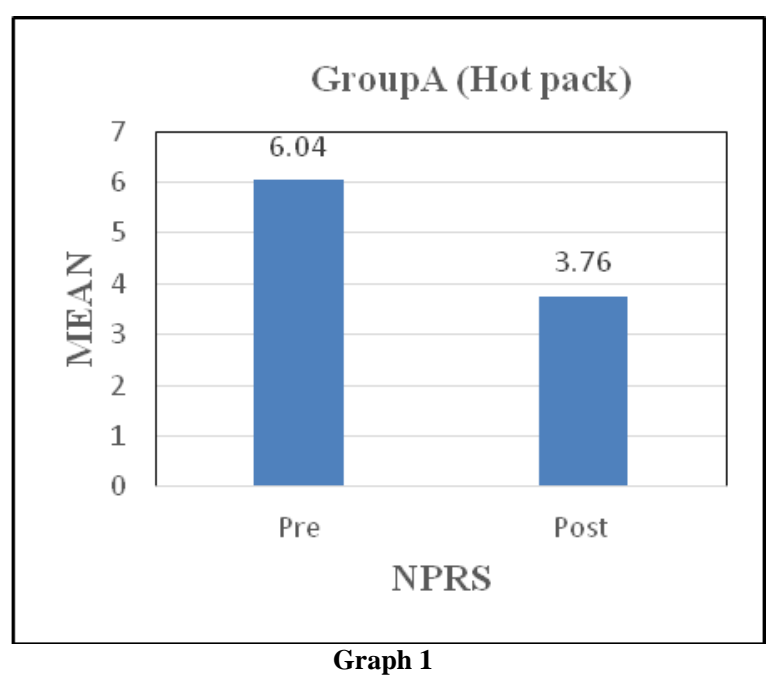

Table 2 - Pre and Post Kinesiotape and Hot Pack application

\begin{tabular}{|l|c|c|c|l|l|}
\hline $\begin{array}{l}\text { Group } \\
\text { B }\end{array}$ & Mean & SD & P value & $\begin{array}{l}\text { T } \\
\text { value }\end{array}$ & $\begin{array}{l}\text { Mean } \\
\text { Difference }\end{array}$ \\
\cline { 1 - 3 } Pre & 6.44 & 1.227 & $<0.0001$ & 13.00 & 3.600 \\
\hline Post & 2.84 & 1.993 & & & \\
\hline
\end{tabular}

The above table shows that there is significant change in Pre and Post Kinesiotape and Hot pack application on pain rating using NPRS scale.

Table 3 - Post Hot Pack and Post Kinesiotape and Hot Pack

\begin{tabular}{|l|l|l|l|l|l|}
\hline Groups & Mean & SD & $\begin{array}{l}\text { P } \\
\text { value }\end{array}$ & $\begin{array}{l}\text { T } \\
\text { value }\end{array}$ & $\begin{array}{l}\text { Mean } \\
\text { Difference }\end{array}$ \\
\hline $\begin{array}{l}\text { Group } \\
\text { A }\end{array}$ & 3.76 & 1.393 & 0.06 & 1.892 & 0.9200 \\
\cline { 1 - 3 } $\begin{array}{l}\text { Group } \\
\text { B }\end{array}$ & 2.84 & 1.993 & & & \\
\hline
\end{tabular}

The above table shows that there is NO quite significant difference after post application of Hot Pack and Post application of KTape and Hot Pack on Pain rating using NPRS scale.
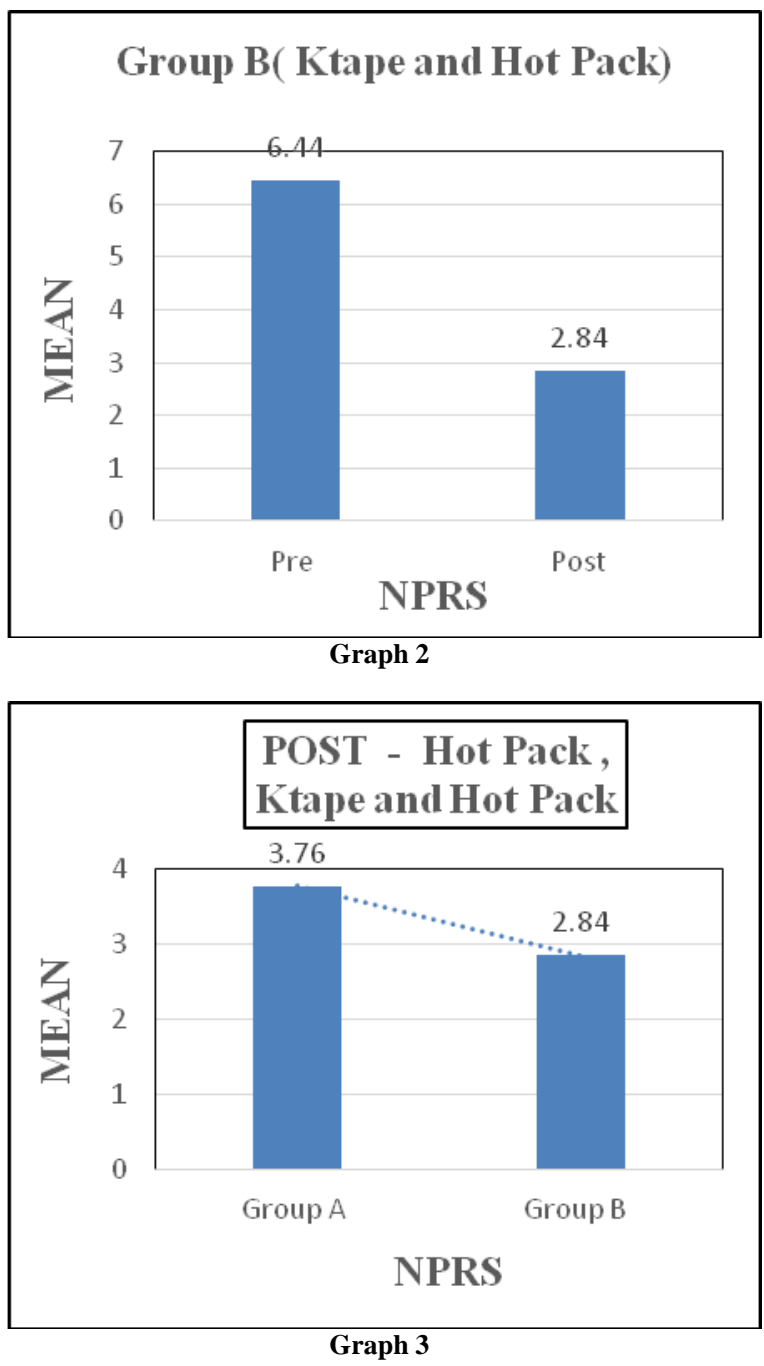

\section{DISCUSSION}

Primary Dysmenorrhea without pelvic pathology is one of the most common complaints in women's medicine. Some women have severe back pain. Abdominal pain is often accompanied by nausea and vomiting, headache and an unpleasant general feeling. Release of prostaglandins and other inflammatory mediators in the uterus cause the uterus to contract. These substances are thought to be a major factor in primary dysmenorrhea.

This study aimed to find out if there is any immediate adjunct effect of Kinesiotape on Hot Pack on pain in primary dysmenorrhea. The Results indicated that both the groups showed significant 
improvement in relieving pain in primary dysmenorrhea. $(\mathrm{p}<0.05)$.

For Group A, these findings attributed to the effect of superficial heating agent. Hot Pack which reduces the pain by dilation of small blood vessels, increase in the local blood flow and activation of pain gate mechanism. For Group B, there is an effect of Ktape along with hot pack. The application of the Ktape stimulates the mechanoreceptors in the skin. These proprioceptive afferents run to the dorsal horn and inhibit the relaying of nociception, thus reducing the pain.

On comparison in between the groups by unpaired $t$ test there is no significant difference found in improvement of relieving pain $(\mathrm{p}>0.05)$. On comparison of mean of both the groups there is some difference found, but statistically it is not significant. Hence there is no additional immediate effect of Ktape found.

This can be due to the reason that in this study immediate effects have been investigated. In previous literature, one study done by Jung-Hyun Choi (2017) from Korea proposed the effects of kinesiotaping and hot packs on premenstrual syndrome in females. The study concluded that Kinesiotaping is an effective method for female college students with premenstrual syndrome. But in this study, the experimental groups underwent kinesiotaping from 10 days before the estimated period date of menstruation until the first day of the period. ${ }^{(5)}$

Another study done by Chaegil Lim et al (2013) proposed the effect of kinesiotaping and spiral taping on menstrual pain and premenstrual syndrome. The study concluded that kinesiotaping had significant effects on menstrual pain, while spiral taping was effective at alleviating both menstrual pain and accompanying premenstrual syndrome. But in this study, subjects underwent $\mathrm{K}$ - taping a total of six times twice a week for about three weeks starting from 14 days before menstruation until its end. ${ }^{(6)}$
Another study done by Sucheta Golhar et al (2020) proposed the effect of kinesiotaping on pain in females with primary dysmenorrhea. The study concluded that kinesiotaping is effective in reducing pain in primary dysmenorrhea. In this study, tape was kept throughout the cycle and removed after the cycle stopped. VAS scale was taken before starting with the treatment. After intervention, VAS scale was taken at the end of the cycle and noted down. ${ }^{(7)}$

One of the musculoskeletal study on lateral epicondylitis by Alisha Gracias, S.Shobhalakshmi concluded that there was significant improvement in pain pressure and grip strength after the immediate application of KT in the experimental group as compared to the control group. ${ }^{(8)}$

Another study done by Sarfaraz Alam et al. concluded that kinesiotape did not cause significant difference in shoulder muscle strength and range of motion in healthy individuals. This could be as the duration of muscle taping may not be enough to produce greater muscle strength. Slupik et al pointed out the participation of a muscle's motor units increased maximally after 24 hours of KT. ${ }^{(9)}$

One study done by Soheila Abbasi from Iran concluded that Kinesiotape can decrease pain and disability scores in individuals with nonspecific chronic low back pain after 3 days of kinesiotape application. ${ }^{(10)}$

So, there is conflict in literature about immediate effect of kinesiotape for relieving pain.

In our study, immediate effect has been checked for relieving pain in primary dysmenorrhea, so it is clinically effective for relieving pain, but this duration is not enough to produce a statistically significant effect on pain. K-Taping requires some duration of period for the effectiveness on pain.

So, this study suggested that Hot Pack is effective for relieving pain in primary dysmenorrhea. 


\section{CONCLUSION}

Study concludes that clinically Hot Pack as well as Kinesiotape both are effective in alleviating pain in primary dysmenorrhea. Kinesiotape showed no significant adjunct effect as compared to only hot pack.

\section{Limitation of study}

1. Small population were included in the study.

2. Population were included only based on history and ultrasonography was not performed in some individuals to rule out other gynecological conditions.

\section{Future Scope of study}

1. Study can be done on larger population.

2. Study can also be done in Secondary Dysmenorrhea other than age group of 18-25 yrs.

\section{Clinical Implication}

Hot Pack and Kinesiotape are effective in reducing pain in primary dysmenorrhea. As both are effective and have no side effects, girls can use these alternatives in alleviating their menstrual pain based on individual factors like cost, availability, accessibility etc

\section{Acknowledgement: None}

\section{Conflict of Interest: None}

\section{Source of Funding: None}

\section{Ethical Approval: Approved}

\section{REFERENCES}

1. DC Dutta. Textbook of Gynaecology. $6^{\text {th }}$ edition. New Delhi: Jaypee Brothers Medical Publishers, 2013. 178-184.

2. Angela Forster, Nigel Palastanga. Clayton's Electrotherapy Theory and Practice. Ninth edition. Delhi: A.I.T.B.S. Publishers, 2006.
3. Val Robertson,Alex Ward,John Low,Ann Reed, Electrotherapy explained principles and practice,4th edition. Edinburg: Elsevier Butterworth -Heinemann,2006.

4. Birgit Kumbrink.K Taping an illustrated guide. Berlin Heidelberg: Springer, 2012. 128-129.

5. Jung -Hyun Choi, PhD, PT. Effects of kinesio taping and hot packs on premenstrual syndromes in females. The Journal of Physical Therapy Science. 2017; 29(9):1514-1517.

6. Chaegil Lim, PT, Yongnam Park, PT, Youngsook Bae, PT, The Effect of the Kinesio Taping and Spiral Taping on Menstrual Pain and Premenstrual Syndrome. The Journal of Physical Therapy Science.2013;25(7):761-764.

7. Devika Bhosale, Dr. Sucheta Golhar and Dr. Mahendra Shende. Effect of Kinesio taping on pain in females with primary dysmenorrhea. International Journal of Applied Research.2020;6(8):187-189.

8. Alisha Gracias, S. Shobhalakshmi, Immediate Effect of Kinesio Taping on Pain and Grip Strength in Individuals with Lateral Epicondylitis. Indian Journal of Physical Therapy and Research .2019; 1(1): 24-28.

9. Sarfaraz Alam, et al. Immediate effect of Kinesiotaping on shoulder muscle strength and range of motion in healthy individuals: A randomised trial.Hong Kong Physiotherapy Journal.2015; 33(2) :80-88.

10. Soheila Abbasi, Mohammad -Reza Hadian Rasanani et al. Short Term effect of kinesiology taping on pain, functional disability and lumbar proprioception in individuals with nonspecific chronic low back pain: a double-blinded, randomized trial. Chiropractice and Manual Therapies. $2020 ; 28(63): 1-10$.

How to cite this article: Joshi R, Pachpute S. Immediate effect of hot pack versus kinesiotape and hot pack on pain in primary dysmenorrhea. Int J Health Sci Res. 2021; 11(8):11-16. DOI: https://doi.org/10.52403/ijhsr.20210803 